\title{
In vitro evaluation of the marginal and internal discrepancies of different esthetic restorations
}

\author{
Amal Abdelsamad SAKRANA
}

Fixed Prosthodontics Department, Faculty of Dentistry, Mansoura University, Mansoura, Egypt; Fixed Prosthodontics Department, College of Dentistry, King Saud bin Abdulaziz University for Health Sciences, Riyadh, Saudi Arabia.

Corresponding address: Amal Abdelsamad Sakrana - King Saud bin Abdulaziz University for Health Sciences - College of Dentistry - Department of Fixed Prosthodontics - Riyadh, Kingdom of Saudi Arabia - Phone: (+966) 050-6426083 - e-mail: amal.sakrana@yahoo.com

Submitted: January 24, 2013 - Modification: May 23, 2013 - Accepted: July 4, 2013

\section{ABSTRACT}

\begin{abstract}
$\mathrm{O}$ bjective: This study examined the fit of two types of all-ceramic single crowns and indirect composite resin full coverage crowns. Material and Methods: Thirty intact human mandibular first premolars were selected for this study and prepared using a machine to standardize the dimensions and randomly divided into 3 groups. Slip cast (IC) (In-Ceram Zirconia, Vita Zahnfabrik), copy-milled zirconia (CM) (ICE, Zirkonzahn) and indirect composite resin crowns (NECO, HeraeusKulzer, Hanau, Germany), (N=30, 10 per group) were fabricated according to each manufacturer's recommendations. Before cementation, discrepancies were measured at the marginal zone in each crown. Crowns were then cemented with G-Cem capsule self-adhesive luting cement (GC Corporation, Tokyo, Japan). Four positions were marked for each zone (mid-facial, mid-mesial, middistal, and mid-lingual) and three measurements were made at each of the four positions yielding to a total of 12 measurements per crown before and after cementation. The measurements were performed at a different magnification using a stereo microscope (SZ11, Olympus, Japan). Marginal, axial and occlusal zone discrepancies $(\mu \mathrm{m})$ were evaluated after cementation. The data were statistically analyzed using two-way ANOVA and Tukey's test. Results: Before cementation, significantly less marginal discrepancies were noted compared with after cementation in all groups $(p<0.05)$. No significant differences were found within each zone (Marginal= IC: 84.2, NECO: 95.22, CM: 84.22; Axial= IC: 54.22, NECO: 64.2, CM: 55.22; Occlusal= IC: 119.97, NECO: 129.18, CM: 121.15) in the three crown systems $(p>0.05)$. Occlusal zone discrepancies were significantly higher than those of the marginal and axial zones in all groups $(p<0.05)$. Conclusions: Slip cast and copy-milled zirconia crowns showed comparable fit to composite resin crowns in all marginal, axial and occlusal areas.
\end{abstract}

Key words: Dental marginal adaptation. Ceramics. Composite resins.

\section{INTRODUCTION}

The demand for esthetically pleasing dental restorations has made the all-ceramic crown a popular form of restoration. Ceramics with a zirconium oxide framework have become the standard for indirect esthetic restorative materials. These all-ceramic systems have high fracture strength and high survival rates clinically ${ }^{12}$. Moreover, dental ceramics cannot withstand elastic deformation to the same extent as tooth structures or resinous materials. Stress concentrations depend on the geometry of the specimen material, loading conditions, the presence of intrinsic or extrinsic flaws and marginal and internal adaption ${ }^{24}$. However, resin-based luting agents were shown to reduce, yet not completely absorb, intracoronal stresses ${ }^{23,30}$. Two important factors for all-ceramic restorations are strength and marginal adaptation, and if all-ceramic restorations are to be successful, they must satisfy the clinical requirements in both respects. Crowns fabricated with all-ceramic systems may use different techniques ${ }^{7,9}$.

Conventional In-Ceram crowns are fabricated using a slip-casting technique to produce a highstrength core. Slip-cast zirconia initially is partially 
sintered in a furnace and then infiltrated with liquid glass in a second firing process ${ }^{3}$. Copy-milling technologies are used for making an all-ceramic restoration. Some authors reported that the copymilling restoration was less accurate compared with other methods. However, copy-milled single crowns have been shown to be biologically acceptable and have relatively homogenous marginal gaps ${ }^{10}$.

Numerous clinical studies concerning composite resins as indirect restorative materials for inlays and onlays have been carried out, and have shown promising results ${ }^{2,16}$. With regards to full crowns, several clinical studies have been performed, such as Artglass crowns cemented with 2 bond 2 cement and solid bond, showing a 3-year survival rate of $96 \%{ }^{21}$. However, a 5-year clinical study showed that the survival rate for the same type of crowns dropped to $88.5 \%{ }^{15}$.

Indirect composite crowns have a number of advantages over zirconium-oxide-based ceramic crowns. With ceramics, a deep chamfer preparation with a depth of $1-1.5 \mathrm{~mm}$ is recommended ${ }^{17}$ compared to a less invasive tooth preparation of $0.5 \mathrm{~mm}$ chamfer for composite restorations ${ }^{19}$. Composites do not inflict the high levels of abrasion on antagonizing teeth that ceramics are known to $\mathrm{do}^{8,14}$. Moreover, composite resin is a cheaper material.

A new composite resin, NECO (HeraeusKulzer, GmbH, Hanau, Germany), was developed for the manufacturing of all types of indirect dental restorations as an alternative to other indirect restorative materials. The material is designed as an improved version of Artglass, a composite resin material previously introduced in the dental market for the same indication ${ }^{21}$. A previous 3-year clinical study was conducted by Jongsma, et al. ${ }^{12}$ (2012) to determine clinical success and survival rates of NECO used as an indirect restorative material for the manufacturing of posterior full and partial single-unit indirect restorations, without any fiber reinforced or metal substructure or framework. The success and survival percentages of NECO restorations were 84.8 and $91.6 \%$ according to the cement materials used. However, to the knowledge of the authors, no experimental evaluation of the marginal and internal fit of this material was carried out.

A good marginal fit seems to be one of the most important technical factors for the long term success of any restoration. Because a large marginal opening allows more plaque accumulation, gingival sulcular fluid flow, and bone loss, resulting in microleakage, recurrent caries, periodontal disease and decrease of the longevity of the prosthetics restorations $\mathbf{s}^{3,6,16}$. This problem may be aggravated in fixed partial restorations with vital abutments. Nevertheless, clinicians should strive to minimize margin misfit ${ }^{23}$. A marginal gap ranging from 25 to $40 \mu \mathrm{m}$ for cemented restorations has been suggested as a clinical goal ${ }^{1}$. However; these measurements are seldom achieved in a clinical scenario $^{29}$. There have been numerous studies of various all-ceramic crown systems with a wide range of marginal openings from 0 to $313 \mu \mathrm{m}$ and a reported mean marginal opening of $155 \mu \mathrm{m}^{20}$. McLean and Von Fraunhofer ${ }^{18}$ (1971) examined more than 1,000 crowns after a 5-year period and concluded that a marginal opening of $\leq 120 \mu \mathrm{m}$ was clinically acceptable.

With these considerations, the purpose of this study was to compare the marginal opening and internal adaptation of zirconia-based restorations and indirect composite resin full coverage restorations which are commonly used for the fabrication of single-crown restorations. However, measurement data for the marginal and internal fit of the copy milling ICE Translucent zirconia (Zirkonzahn $\mathrm{GmbH}$, Bruneck, Italy) and indirect composite resin (NECO, HeraeusKulzer,GmbH, Hanau, Germany) have not been reported.

\section{MATERIAL AND METHODS}

\section{Experimental design}

Thirty caries-free human mandibular right first premolars were selected for this study. These teeth were extracted for orthodontic purposes. The collected teeth were cleaned and stored in $0.5 \%$ chloramine solution at $4^{\circ} \mathrm{C}$ for a maximum of 6 months after extraction. Approval to use human teeth was obtained from the Research Ethics Committee at Mansoura University, Egypt. These teeth, which were relatively comparable in size, were embedded in upright position inside plastic rings using auto polymerized acrylic resin (Ostron 100, GC Dental Products Corp., Japan), 2 mm away from the cervical line of the teeth. The long axis of the tooth was oriented perpendicular to the surface of the block.

Before tooth preparations, an additional silicone (Zhermack Spa, Via Bovazecchino, Italy) impression was made of each tooth. The external form of each tooth was recorded using a shell of $1.0-\mathrm{mm}$ thick thermoplastic sheet (Easy-Vac Gasket, Goyang-si, Korea). The shells were made with a thermoforming unit (ECONO-VAC, Buffalo Dental Mfg. Co., USA) and subsequently used to replicate the original contours of the teeth. The silicone impressions were sectioned vertically and used as indexes to monitor occlusal and axial tooth reductions during the teeth preparation.

The preparations were performed on a lathe cutting machine (AB Machine Tools LTD. SGia M/C No. 17531, Edmonton, Canada) using a cross-slide carbide insert tool at a speed of $400 \mathrm{rpm}$ under cool 
water. Machine cut to a standardized dimension for all the samples, resulting in an approximately $1 \mathrm{~mm}$ shoulder margin with rounded internal margins, $6^{\circ}$ tapered angles and an approximate height of $4 \mathrm{~mm}$ (shoulder to top) (Figure 1).

Impressions were made with addition silicon (vinylpolysiloxane) impression material (Elite HD, Zhermack Spa, Via Bovazecchino, Italy) for each prepared tooth. Working dies were fabricated with type IV dental stone according to manufacturer's recommended water/powder ratio. One layer of die hardener and die spacer were applied to the dies, which were randomly divided into three groups of ten each.

Group 1: 10 In-Ceram zirconia crowns (Vita Zahnfabrik-Bad Säckingen, Germany) were fabricated by the slip casting technique. The crowns were subjected to glass-infiltration firing and then fitted to the dies. Finally, they were veneered with VITA VM9 ceramic (Vita Zahnfabrik-Bad Säckingen, Germany).

Group 2: 10 Copy milling zirconia crowns were fabricated from ICE Translucent zirconia blocks (ICE Zirkon, Zirkonzahn GmbH, Bruneck, Italy) according to the manufacturer's directions.

Group 3: 10 light curing nano hybrid composite resin crowns were fabricated from NECO (HeraeusKulzer, Hanau,GmbH, Germany) by building up the tooth using a layering technique. Initially, a layer of the composite resin was placed over the prepared surfaces of the dies to form a coping, and then polymerized for 90 seconds in a visible light cure system (Triad ${ }^{\circledR} 2000^{\mathrm{TM}}$, Dentsply, USA). Additional composite resin material was then applied incrementally to reduce polymerization shrinkage. Each addition was polymerized for 90 seconds. The original external crown contours were duplicated by filling the previously made thermoplastic shells with a sufficient quantity of composite resin and seating them on their respective dies with copings in place. The final polymerization period was 180 seconds. The crowns were finished and polished at low speed, in accordance with the manufacturer>s instructions, using a recommended

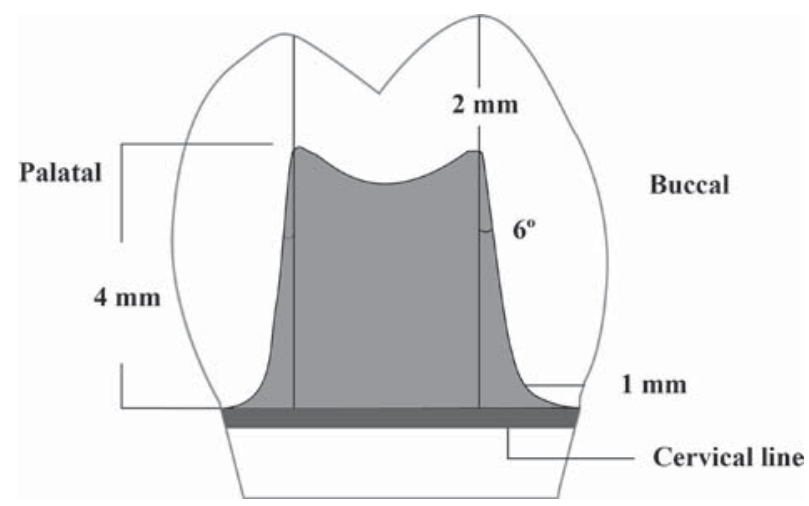

Figure 1- Schematic diagram shows the prepared tooth rotary instrument.

After fabrication, all restorations were examined for deformity, debris and steam cleaned. The definitive restorations were re-evaluated on the die and fit to their corresponding prepared teeth under the original 2.6X magnification for marginal discrepancy by both visual and tactile methods. Restorations with a margin deemed visually unacceptable were rejected. An explorer was used to detect the presence of overcontour, undercontour, or marginal gaps. Overcontoured restorations were adjusted with a finishing instrument, restorations with a marginal gap or undercontoured were rejected and remade.

The intaglio surfaces of the crowns were treated with 50- $\mu \mathrm{m}$ aluminum oxide particles (Ney, Barkmeyer Division, Yucaipa Ca, USA) at a pressure of 2.8 bars for $5 \mathrm{~s}$ at a distance of $10 \mathrm{~mm}$, then were rinsed with air/water spray for $30 \mathrm{~s}$ and air-dried.

The marginal fit was determined before cementation by setting the crowns on its corresponding prepared tooth. Four positions were marked (mid facial, mid mesial, mid distal, mid lingual), three measurements were taken at each of the four positions for a total of 12 measurements per crown ${ }^{28}$. After that the finished crowns were cemented with G-Cem capsule self-adhesive luting cement (GC Corporation, Tokyo, Japan), under 50 $\mathrm{N}$ static load for 10 minutes. The excess cement was removed upon setting, application and photo cured for $10 \mathrm{~s}$ from each direction according to the manufacturer's directions.

Twenty-four hours after cementation, the teeth were sectioned centrally from buccal to lingual and from mesial to distal according to the pencil-lines that were marked at the middle of teeth, thus resulting in 4 specimens to be evaluated for each tooth.

The marginal fit was determined after cementation. Four positions were marked (mid facial, mid mesial, mid distal, mid lingual), three measurements were taken at each of the four positions for a total of 12 measurements per crown, as done before cementation. Internal gaps were also measured at the marginal, axial and occlusal measurement locations. The cut sections were examined under a stereo microscope (SZ11, Olympus, Japan) at 40X magnification. Marginal accuracy was measured as the maximum distance between the finish surface angle of the underlying prepared tooth and the cervical margin of the crowns. Internal adaptation (also defined as cement film thickness) was measured as the maximum distance (perpendicular line to the prepared surface) between the inner surface of the crown and the outer surface of the prepared tooth at three fixed locations. 


\section{Statistical analysis}

Statistical analysis was performed using SPSS 11.0 software for Windows (SPSS Inc., Chicago, IL, USA). A two-way analysis of variance (ANOVA) was carried out to detect statistical differences of the marginal gaps between the three tested groups. $P$ values less than 0.05 were considered to be statistically significant in all tests. One-way analysis of variance (ANOVA) was also performed for comparisons between the mean values of marginal, occlusal, and axial internal adaptation $(\mu \mathrm{m})$ of the three studied groups.

\section{RESULTS}

A total of 30 restorations were fabricated with 12 measurements taken per crown, for a total of 360 measurements before cementation and another 360 after cementation. The mean marginal gap discrepancies are shown in Table 1. Two-way ANOVA test was performed to compare the vertical marginal openings before and after cementation of the three tested groups. Two-way ANOVA test showed statistically significant differences between the mean values of the vertical marginal openings of the three tested groups, where $F=74.6$ and $p<0.05$.

The In-Ceram zirconia was superior and presented the best adaptation when compared to the other two crown systems. Conversely, NECO composite resin crowns showed the lowest levels of marginal adaptation after cementation. However, copy-milled zirconia revealed less marginal adaptation than In-Ceram zirconia and NECO composite resin before cementation. After cementation, the marginal adaptation of copymilled zirconia was better than NECO composite resin and almost similar to the In-Ceram zirconia.

Table 2 represents the one-way ANOVA performed for comparisons between the mean values of internal adaptation $(\mu \mathrm{m})$ at different locations (marginal, axial and occlusal) within each studied group. No significant difference was found within each zone (Marginal= IC: 84.2, NECO: 95.22, CM: 84.22; Axial= IC: 54.22, NECO: 64.2, CM: 55.22; and Occlusal= IC: 119.97 , NECO: 129.18, CM: 121.15) in the three crown systems $(p<0.05)$. However, occlusal zone discrepancies were significantly higher than those of marginal and axial zones in all groups $(p<0.05)$.

Table 1- Two-way ANOVA of the vertical marginal openings before and after cementation

\begin{tabular}{ccccc}
\hline Group & & In-Ceram zirconia & $\begin{array}{c}\text { NECO composite } \\
\text { resin }\end{array}$ & Copy milled zirconia \\
$\mathbf{N}$ & & $\mathbf{1 0}$ & $\mathbf{1 0}$ & $\mathbf{1 0}$ \\
\hline \multirow{2}{*}{ Mean } & Before & 56.3 & 56.16 & 60.16 \\
& After & 84.2 & 95.22 & 84.22 \\
$\pm S D$ & Before & 3.55 & 3.24 & 4.4 \\
& After & 2.40 & 4.40 & 3.5 \\
\hline$P^{* *}$ & 74.68 & & & \\
\hline
\end{tabular}

$\mathrm{p}^{* *}=$ Significant difference

$\mathrm{SD}=$ Standard Deviation

Table 2- One-way ANOVA for comparisons between the mean values of occlusal internal adaptation ( $\mu \mathrm{m})$ of the three studied groups

\begin{tabular}{cccccccccc}
\hline Surface & Group & Occlusal & Group & Group IC & Group & Axial & & \multicolumn{3}{c}{ Marginal } \\
CM & NECO & & GM & NECO & Group IC & $\begin{array}{c}\text { Group } \\
\text { CM }\end{array}$ & $\begin{array}{c}\text { Group } \\
\text { NECO }\end{array}$ & Group IC \\
N & $\mathbf{1 0}$ & $\mathbf{1 0}$ & $\mathbf{1 0}$ & $\mathbf{1 0}$ & $\mathbf{1 0}$ & $\mathbf{1 0}$ & $\mathbf{1 0}$ & $\mathbf{1 0}$ & $\mathbf{1 0}$ \\
\hline Mean & 121.15 & 129.18 & 119.97 & 55.22 & 64.2 & 54.22 & 84.22 & 95.22 & 84.2 \\
\pm SD & $\mathbf{0 . 9 8}$ & 1.13 & 1.29 & 1.17 & 0.89 & 0.83 & 0.72 & 0.18 & 1.21 \\
\hline
\end{tabular}

$\mathrm{IC}=$ In Ceram

NECO=Composite resin

$\mathrm{CM}=$ Copy milling

$\mathrm{SD}=$ Standard Deviation 


\section{DISCUSSION}

An attempt was made to mimic the clinical scenario as closely as possible. Natural teeth were used in this study to simulate the clinical condition by providing microstructure to the luting cement that is nearly identical to the clinical situation. Standardized tooth preparation was done in this study to accurately control the variables of preparation dimensions, degree of axial wall taper, and the finish line dimensions, however, any variation in it leads to a change in marginal fit $^{3}$. By the prepared tooth impression, fabricated stone dies, and having the restoration made in a commercial laboratory, many elements of clinical error could have occurred. The definitive restoration was then evaluated on the prepared tooth and the patient analog. Using this method, it was necessary to evaluate each crown as if it were to be placed intra orally. Therefore, exclusion criteria were applied at the clinical level.

Evaluation of the marginal fit of each crown at four preselected locations were done by using the direct view method, since it was a convenient, easy and rapid method for measuring. This study used the cross-sectional technique to obtain the data. This technique might lead to a lack of information concerning the precision of fit. It might be questioned if the measured areas represented the precision of fit of the whole specimen. However, several studies used the cross-section technique to evaluate the precision of fit ${ }^{4,5,22}$.

The mean marginal gap of different crown systems reported in the current study was between 56.16 and $60.16 \mu \mathrm{m}$ before cementation and 84.2 and $95.2 \mu \mathrm{m}$ after cementation with composite resin cement. These findings are in agreement with the clinical acceptance of the marginal openings range $(120 \mu \mathrm{m})^{3,18}$. The present study revealed the best marginal fit with the In-Ceram zirconia restoration. This result coincided with Torabi Ardekani, et al. ${ }^{25}$ (2012), however, our finding included slightly significant higher marginal gaps but still lower than the measurements done by Wolfart ${ }^{27}$ (2003). Moreover, both conventional In-Ceram zirconia and copy-milled zirconia crowns can be produced with a clinically sufficient marginal accuracy compared to composite resin crowns and these results are supported by many other studies ${ }^{11,26}$.

With regard to the marginal fit evaluation before and after cementation for each group studied. In each group under study, it was found that the marginal fit were significantly increased after cementation. This could be attributed to the increase of hydraulic pressure of the resin luting cement. Also, the result of this study was supported by other studies, which found a significant increase in the marginal fit after cementation and attributed this to the viscosity of the luting cement used which could affect the seating of the restoration and the geometric forms of the crown abutment ${ }^{13,27}$.

\section{CONCLUSIONS}

Within the limitations of this study, it can be concluded that both the slip cast and copy-milled zirconia all-ceramic crown systems demonstrated a comparable and acceptable marginal, axial and occlusal fit to those of composite resin crown, all being within the range of clinically accepted values.

\section{DISCLAIMER}

The author has no commercial relationship with any of the manufacturers listed in this article.

\section{REFERENCES}

1- American Dental Association. ANSI/ADA Specification No. 8 for zinc phosphate cement. In: Guide to dental materials and devices. $5^{\text {th }}$ ed. Chicago: ADA; 1970. p. 87-8.

2- Barone A, Derchi G, Rossi A, Marconcini S, Covani U. Longitudinal clinical evaluation of bonded composite inlays: a 3-year study. Quintessence Int. 2008;39:65-71.

3- Beschnidt SM, Strub JR. Evaluation of the marginal accuracy of different all-ceramic crown systems after simulation in the artificial mouth. J Oral Rehabil. 1999;26:582-93.

4- Beuer F, Aggstaller H, Edelhoff D, Gernet W, Sorensen J. Marginal and internal fits of fixed dental prostheses zirconia retainers. Dent Mater. 2009;25:94-102.

5- Bindl A, Mörmann WH. Fit of all-ceramic posterior fixed partial denture frameworks in vitro. Int J Periodontics Restorative Dent. 2007;27:567-75.

6- Buso L, Hilgert E, Neisser MP, Bottino MA. Marginal fit of electroformed copings before and after the coction of the porcelain. Braz J Oral Sci. 2004;3(8):409-13.

7- Cehreli M, Kökat A, Akça K. CAD/CAM zirconia vs. slip-cast glass infiltrated alumina/zirconia all ceramic crowns: 2-year results of randomized controlled clinical trial. J Appl Oral Sci. 2009;17(1):49-55.

8- Etman MK, Woolford M, Dunne S. Quantitative measurement of tooth and ceramic wear: in vivo study. Int J Prosthodont. 2008;21:245-52.

9- Gonzalo E, Suárez MJ, Serrano B, Lozano JF. A comparison of the marginal discrepancies of zirconium and metal ceramic fixed dental prostheses before and after cementation. J Prosthet Dent. 2009;102:378-84.

10- Groten M, Axmann D, Probster L, Weber H. Determination of the minimum number of marginal gap measurements required for practical in-vitro testing. J Prosthet Dent. 2000;83:40-9.

11- Holden JE, Goldstein GR, Hittelman EL, Clark EA. Comparison of the marginal fit of pressable ceramic to metal ceramic restorations. J Prosthodont. 2009;18:645-8.

12- Jongsma LA, Kleverlaan CJ, Feilzer AJ. Clinical success and survival of indirect resin composite crowns: results of a 3-year prospective study. Dent Mater. 2012;28:952-60.

13- Kern M, Schaller H-G, Strub JR. Marginal fit of restorations before and after cementation in vivo. Int $\mathrm{J}$ Prosthodont. 1993;6:585-91.

14- Krämer N, Kunzelmann KH, Taschner M, Mehl A, Garcia-Godoy F, Frankenberger R. Antagonist enamel wears more than ceramic inlays. J Dent Res. 2006;85:1097-100. 
15- Lehmann F, Spiegl K, Eickemeyer G, Rammelsberg P. Adhesively luted, metal-free composite crowns after 5 years. ] Adhes Dent. 2009;11:493-8.

16- Manhart J, Chen H, Hamm G, Hickel R. Buonocore Memorial Lecture. Review of the clinical survival of direct and indirect restorations in posterior teeth of the permanent dentition. Oper Dent. 2004;29:481-508.

17- Manicone PF, Rossi Iommetti P, Raffaelli L. An overview of zirconia ceramics: basic properties and clinical applications. J Dent. 2007;35:819-26.

18- McLean JW, von Fraunhofer JA. The estimation of cement film thickness by an in vivo technique. Br Dent J. 1971;131:107-11. 19- OhImann B, Gruber R, Eickemeyer G, Rammelsberg P. Optimizing preparation design for metal-free composite resin crowns. J Prosthet Dent. 2008;100:211-9.

20- Pera P, Gilodi S, Bassi F, Carossa S. In vitro marginal adaptation of alumina porcelain ceramic crowns. J Prosthet Dent. $1994 ; 72: 585-90$.

21- Rammelsberg P, Spiegl K, Eickemeyer G, Schmitter M. Clinical performance of metal-free polymer crowns after 3 years in service. J Dent. 2005;33:517-23.

22- Reich S, Wichmann M, Nkenke E, Proeschel P. Clinical fit of all-ceramic three-unit fixed partial dentures, generated with three different CAD/CAM systems. Eur J Oral Sci. 2005;113:174-9.
23- Rossetti PH, Valle AL, Carvalho RM, Goes MF, Pegoraro LF. Correlation between margin fit and microleakage in complete crowns cemented with three luting agents. J Appl Oral Sci. 2008;16(1):64-9.

24- Schaefer O, Watts DC, Sigusch BW, Kuepper H, Guentsch A. Marginal and internal fit of pressed lithium disilicate partial crowns in vitro: a three-dimensional analysis of accuracy and reproducibility. Dent Mater. 2012;28:320-6.

25- Torabi Ardekani K, Ahangari AH, Farahi L. Marginal and internal fit of CAD/CAM and slip-cast made zirconia copings. J Dent Res Dent Clin Dent Prospects. 2012;6(2):42-8.

26- Vult von Steyern $P$, Carlson $P$, Nilner K. All-ceramic fixed partial dentures designed according to the DC-Zirkon technique. A 2-year clinical study. J Oral Rehabil. 2005;32:180-7.

27- Wolfart S, Wegner SM, Al-Halabi A, Kern M. Clinical evaluation of marginal fit of a new experimental all-ceramic system before and after cementation. Int J Prosthodont. 2003;16:587-92.

28- Yeo IS, Yang JH, Lee JB. In vitro marginal fit of three allceramic crown systems. J Prosthet Dent. 2003;90:459-64. 29- Yildiz C, Vanlioğlu B, Evren B, Uludamar A, Ozkan Y. Marginalinternal adaptation and fracture resistance of CAD/CAM crown restorations. Dent Mater J. 2013;32:42-7.

30- Yüksel E, Zaimoğlu A. Influence of marginal fit and cement types on microleakage of all-ceramic crown systems. Braz Oral Res. $2011 ; 25(3): 261-6$. 